\title{
General type industrial temperature system control based on fuzzy fractional-order PID controller
}

\author{
Lu Liu $^{1}$ - Dingyu Xue ${ }^{2}$. Shuo Zhang ${ }^{3}$
}

Received: 3 January 2021 / Accepted: 8 June 2021

(c) The Author(s) 2021

\begin{abstract}
A fuzzy fractional-order PID control algorithm for a general type industrial temperature control system is proposed in this paper. In order to improve the production quality and controlled model accuracy, a fractional-order elementary system is used to describe the temperature control process. The gain coefficients of the proposed fractional-order PID controller is updated online based on a set of fractional-order fuzzy rules which are defined by Mittag-Leffler functions and follow fat-tailed distributions. Therefore, the proposed controller parameters could be auto-tuned according to model uncertainties, noise disturbance, random delay, and etc. Examples of the studied temperature control systems are shown to verify the effectiveness of the proposed controller. The superiority of fractional calculus is fully explored in the presented control methodology. The controlled temperature profile with the proposed algorithm could realize more satisfactory dynamic performance, better robustness respect to environment changes caused by internal and external disturbance.
\end{abstract}

Keywords Fractional calculus · Fuzzy logic control · Fractional-order PID control

\section{Introduction}

In industrial processes, the production quality and efficiency are always influenced a lot by the run-to-run temperature control [1]. Therefore, the dynamic performance, robustness and accuracy of temperature control becomes one of the most decisive elements impacting product quality as well as operation safety. The temperature control performance of industrial thermal systems are usually affected by different complicated factors, for instance, pressure impact, load variations, gas flow impact, measurement noise. These factors make this kind of system hard to be modelled accurately. But

Shuo Zhang

zhangshuo1018@nwpu.edu.cn

Lu Liu

liulu12201220@nwpu.edu.cn

Dingyu Xue

xuedingyu@mail.neu.edu.cn

1 School of Marine Science and Technology, Northwestern Polytechnical University, Xi' an 710072, China

2 Department of Information Science and Engineering, Northeastern University, Shenyang 110819, China

3 School of Mathematics and Statistics, Northwestern Polytechnical University, Xi' an 710072, China since the recipes of temperature control are always repeated and consist of similar stages, simple models fitting from the measured input-output data are used frequently for controller design with the overall consideration of different internal and external disturbance [2].

Most of the temperature control processes were modelled or approximated by the first-order elementary model in the previous studies [2-4]. However, with the growing demand of production quality and efficiency, some of the complex temperature control stages may not be described adequately by this kind of elementary model. Fractional-order elementary model with an extra fractional order may provide more flexibility to represent the dynamic behaviors of practical temperature control process [4]. Therefore, in this paper, a fractional-order elementary model is used to represent a general type of industrial temperature control system, which also includes the first-order elementary model as a special case [5].

The widely used control methods for temperature control includes classic control and intelligent control [1,8]. Among these, the PID controller is one of the most commonly applied classic control methods. It has the advantages of simple structure, easy to be understood, implemented and tuned, etc.

The Fractional-order PID (FOPID or $\mathrm{PI}^{\lambda} \mathrm{D}^{\mu}$ ) type controller is an extension of PID controller which has two

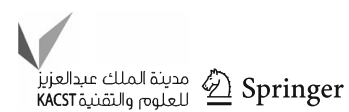


extra tuning parameters, namely integral order $\lambda$ and differential order $\mu[6,7]$. It also has the similar advantages with the PID controller, such as a simple structure. The two additional parameters offer extra flexibility in satisfying controller design specifications, for example, the frequency domain specifications of closed-loop systems. Moreover, the controlled system with the FOPID controller has a certain memory, which can adjust the control performance appropriately according to the historical information and potentially improve system transient performance and robustness. Currently, the FOPID controller has already been applied in some practical applications. Many studies show that FOPID controllers outperform the other controllers in industrial processes [12-15]. The tuning and auto-tuning method of FOPID controller for industry applications has been studied in [12] by Monje et al. A two degree-of-freedom FOPID controller was proposed by Pachauri et al. for temperature control of fermentation process [13]. Another modified IMC-PID controller applied on bioreactor temperature control process has been presented in [14]. Qin et al. proposed a kind of FOPID controller and applied it on the temperature control of vegetable green houses in [15].

The effectiveness of fuzzy logic controller (FLC) has also been proved in some complicated temperature control processes [16,17]. FLCs provide more robust performances and are less sensitive to parameter variations compared with other controllers [18]. After the PID type controller parameters are achieved according to certain requirements, the control performance may be quite sensitive to unpredictable disturbance or environment change. Under the circumstances, a fuzzy controller is more effective for self-adapting. But the controlled system usually is hard to achieve a high precision performance. Therefore, the combination of FOPID controller and FLC could simultaneously guarantee the high precision dynamic performance and robustness of industrial control systems, such as the temperature control process. Different design approaches and applications of fractional-order fuzzy PID (FFuzzy PID) controllers have already been studied [19-22]. Tajjudin et al. designed a self-tuning fuzzy FOPI controller and applied it in the steam distillation process [17]. Das et al. proposed an FFuzzy PID controller based on different integral performance indices and applied the controller to various kinds of controlled systems including linear and nonlinear ones [19]. A variable order FFuzzy PID controller whose five parameters could be tuned online simultaneously with respect to system parameter changes was presented by Liu et al. [20]. An FFuzzy PID controller was applied to a Multi-Input-Multi-Output (MIMO) robotic manipulator by Sharma et al. and produced more superior control performance than conventional controllers [22]. An interval type-2 FFuzzy PID controller was studied in [23] with its performance evaluation by Kumar et al.
However, most of the existing FFuzzy PID controllers are straightforward combinations of FOPID controllers and FLCs. The fractional nature is not integrated in their control logic, so the superiority of fractional calculus has not been fully explored. The common used membership functions in fuzzy rules are always set as a linear type (such as triangle and trapezoid), due to its simple and natural characteristic. For nonlinear distributions, Gaussian membership function is the most popular one. Few study has discussed about how to enhance system control performance by improving the mentioned membership functions. The widely used Gaussian membership functions follow exponential convergence. However, not all the distributions in nature satisfy exponential convergence. It has been proved that heavy-tailed distributions could provide general frameworks for modeling in economics, finance, econometrics, statistics, risk management, insurance and so on [24-27]. Heavy-tailed distributions own a heavier tail (slower convergence rate) than exponential distributions. As a class of heavy-tailed distributions, fat-tailed distribution goes to zero as a power $y^{-a}$, for large $y$. It could be employed to construct a group of novel membership functions. Integrating fat-tailed distribution into membership functions, the fractional-order (FO) membership functions can be obtained. It provides one more optimization dimension which offers more possibilities in improving system transient performance and robustness. In order to further improve the dynamic performance and robustness of the studied general type temperature control system, we design a series of FO membership functions in this paper, which follow fat-tailed distributions. Based on the proposed fuzzy rules, the parameters of FOPID controller can be auto-tuned online. More specifically, according to the controlled process error and its derivative, the parameters of the proposed FOPID controller including the gain coefficients of the proportional, integral and derivative parameters are updated by a fuzzy logic controller. Therefore, when impact factors (such as pressure, gas flow, sensor dynamics, etc) change or measurement noise involves, the temperature control performance could be adjusted automatically according to the environment.

This paper is organized as follows. Firstly, "The process model" introduces the studied temperature control process model and "Fractional calculus" gives the preliminaries of fractional calculus including fractional derivative, MittagLeffler function and their properties. Then, the FFuzzy PID control method is proposed in Sect. "Fuzzy fractional-order PID control", where FO membership functions, fuzzy rules and the design steps of FFuzzy PID controller are given. In Sect. "Examples", examples are shown to verify the effectiveness of the presented methods under different circumstances. At last, the conclusion is drawn in "Conclusion". 


\section{The process model}

Industrial temperature control profile usually consists of different control stages. Each of these stages may be affected by a lot of factors, such as pressure variations, gas flow changes, sensor dynamics, and etc. But a complex model including all these precise factors will be difficult to carry out and hard for controller design. Therefore, most of these stages have been modelled or approximated by a first-order elementary model as shown in Eq. (1) [2].

$G(s)=\frac{K}{T s+1} e^{-L s}$,

where $K$ is the system gain, $T$ is the time constant and $L$ is the time delay.

However, the fractional-order elementary model with an extra fractional order $\alpha$ in Eq. (2) may provide more flexibility and accuracy to represent the dynamic behaviors of the control process.

$G(s)=\frac{K}{T s^{\alpha}+1} e^{-L s}$.

For example, the temperature system we studied which is a plasma etching chamber of a semiconductor manufactor is modeled based on the measured input-output data. The chamber configuration is quite complicated as shown in Fig. 1, but it can be considered as a four zones heater abstractly. So the controlled plant is essentially a four-input-four-output system. Since we have already added some decouplers in the corresponding zones, each of the four zones can be treated as a single-input-single-output system.

The detailed system information and decoupling process can be referred to $[28,29]$. One of the on-site temperature control profiles of this etching chamber is shown in Fig. 2. The data fitting of one representative step which is fitted by a fractional-order elementary model is illustrated in Fig. 3 with $\alpha=0.94$ and $L=[0,2]$ s. It can be seen that the fractional-order elementary model well describe the process with high accuracy. Therefore, it is reasonable to use the fractional-order elementary model to describe a general type of industrial temperature control system. This type of controlled plant has been widely used in modelling and analysis of industrial control processes $[19,20]$.

\section{Fractional calculus}

\section{Fractional derivative}

Three FO differential definitions are frequently used, namely Grunwald-Letnikov definition, Riemann-Liouville definition, and Caputo definition [30,32]. Due to the different

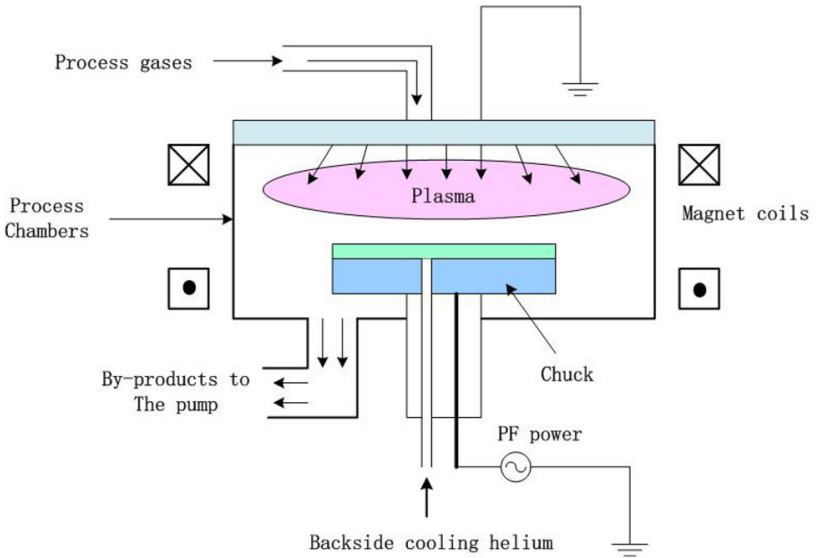

Fig. 1 The internal structure of plasma etching chamber

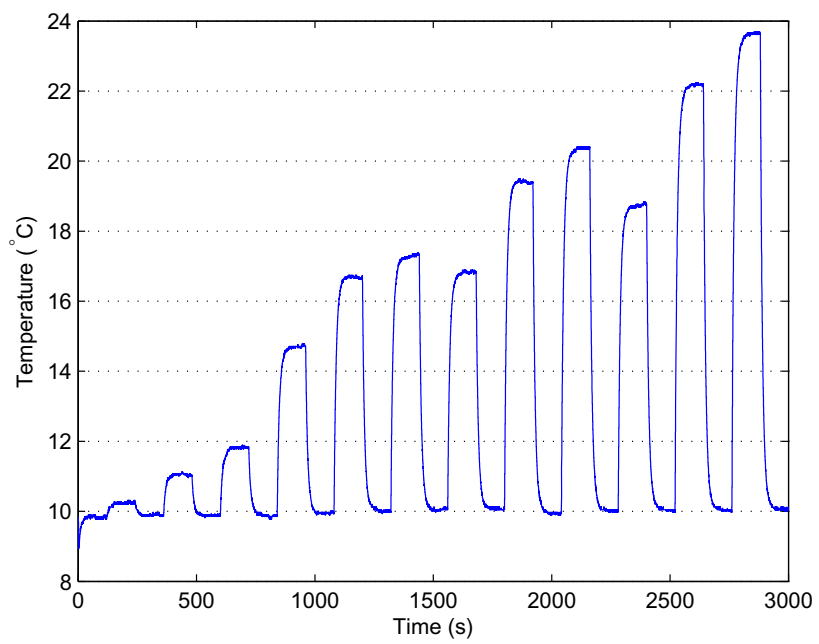

Fig. 2 On-site data profile of temperature control

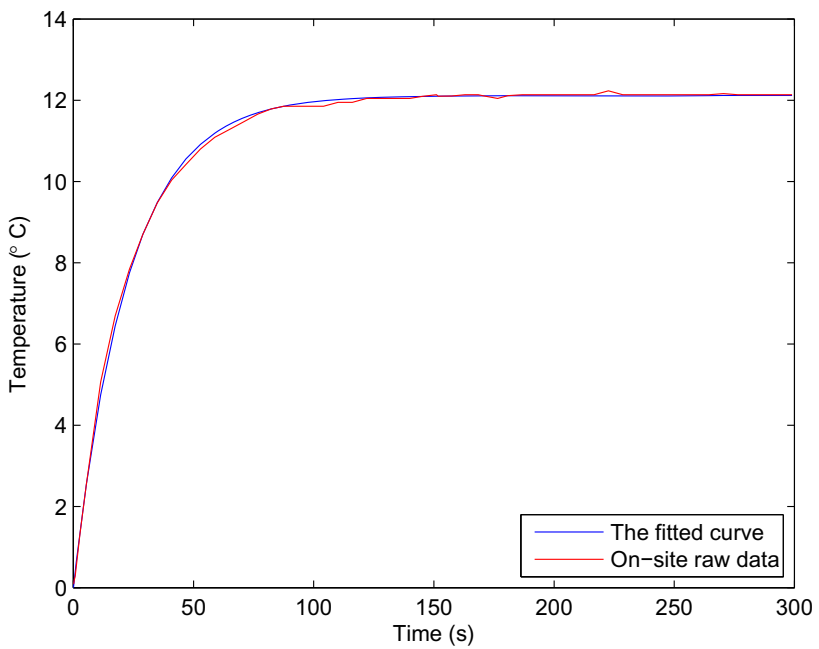

Fig. 3 The fractional-order elementary model fitting

properties of these three FO differential operators, they are applied in different fields of engineering and computing science. However, with null initial conditions, there is no 
difference among these three FO differential operators. We consider the Caputo definition in this paper, because of its wide applications in real physical situations and engineering problems [31,34].

For a function $f(t) \in \mathrm{C}^{n+1}\left(\left[t_{0},+\infty\right], \mathrm{R}\right)$, its Caputo derivative of order $\alpha$ is defined as [31]:

${ }_{t_{0}} D_{t}^{\alpha} f(t)=\frac{1}{\Gamma(n-\alpha)} \int_{t_{0}}^{t} \frac{f^{(n)}(\tau)}{(t-\tau)^{\alpha+1-n}} \mathrm{~d} \tau$,

where $t_{0}$ and $t$ are the lower and upper limits of the operator respectively, $\alpha \in \mathrm{R}$ is the order of Caputo derivative, the positive integer $n$ satisfies $n-1<\alpha \leq n$, and $\Gamma(\cdot)$ is Gamma function defined by

$\Gamma(x)=\int_{0}^{+\infty} t^{x-1} e^{-t} \mathrm{~d} x, \quad\left(x \in R^{+}\right)$.

The Laplace transform of Caputo derivative is:

$$
\begin{aligned}
\mathcal{L}\left\{t_{0} D_{t}^{\alpha} f(t) ; s\right\}= & s^{\alpha} F(s) \\
& -\sum_{k=0}^{n-1} s^{\alpha-k-1} f^{(k)}\left(t_{0}\right), n-1<\alpha<n,
\end{aligned}
$$

where $\mathcal{L}\{\cdot\}$ denotes the Laplace transform, $s$ is the variable operator in Laplace transform, and $F(s)=\mathcal{L}\{f(t) ; s\}$.

\section{Mittag-Leffler function}

As a generalization of the exponential function, MittagLeffler function always exists in the solution of FO differential equations [33]. Consider a two-parameter Mittag-Leffler function, whose power series is defined as [31]:

$E_{\alpha, \beta}(x)=\sum_{k=0}^{\infty} \frac{x^{k}}{\Gamma(\alpha k+\beta)}$,

where $\alpha>0, \beta>0$ and $x \in \mathrm{C}$. Especially $E_{1,1}(x)=$ $e^{x}$ under $\alpha=\beta=1$. The one-parameter Mittag-Leffler function is a special case with $\beta=1$ :

$E_{\alpha}(x)=\sum_{k=0}^{\infty} \frac{x^{k}}{\Gamma(\alpha k+1)}=E_{\alpha, 1}(x)$.

The Laplace transform of two-parameter Mittag-Leffler function represents:

$\mathcal{L}\left\{t^{\beta-1} E_{\alpha, \beta}\left(-\lambda t^{\alpha}\right)\right\}=\frac{s^{\alpha-\beta}}{s^{\alpha}+\lambda},\left(\operatorname{Re}(s)>|\lambda|^{\frac{1}{\alpha}}\right)$, where $t \geq 0, s$ is the variable operator of Laplace domain, and $\operatorname{Re}(\mathrm{s})$ is the real part of $s$.

In addition, we give a property for the one-parameter Mittag-Leffler function in the next Lemma 1.

Lemma 1 [35] The one-parameter Mittag-L-effler function satisfies the following estimates,

$$
\begin{aligned}
E_{\alpha}(z)= & \frac{1}{\alpha} \exp \left(z^{\frac{1}{\alpha}}\right)-\frac{1}{z \Gamma(1-\alpha)} \\
& +O\left(\frac{1}{z^{2}}\right), \text { when } z \rightarrow+\infty,
\end{aligned}
$$

$E_{\alpha}(z)=-\frac{1}{z \Gamma(1-\alpha)}+O\left(\frac{1}{z^{2}}\right)$, when $z \rightarrow-\infty$.

\section{Fuzzy fractional-Order PID control}

In the recent years, the FOPID control has experienced a fast development. A lot of researches have focused on how to tune the FOPID controller and achieved better control performance. The parameters in FOPID controller consist of the fractional orders for integral $(\lambda)$ and derivative $(\mu)$, and the gain coefficients for the proportional $\left(K_{p}\right)$, integral $\left(K_{i}\right)$ and derivative $\left(K_{d}\right)$ parameters. To update these gain coefficients $\left(K_{p}, K_{i}\right.$ and $K_{d}$ ), a fuzzy logic controller is added before the FOPID controller in this paper. So $K_{p}, K_{i}$ and $K_{d}$ become the output scaling factors, which can be updated following the fuzzy rules with respect to the controlled process error $(e)$ and its derivative ( $\mathrm{d} e / \mathrm{d} t)$, simplified by ' $e c$ ' in this paper). The block diagram of the studied FFuzzy PID control is shown in Fig. 4. The 'Fuzzy Logic Controller' block updates the outputs $\left(K_{p}, K_{i}\right.$ and $\left.K_{d}\right)$ mapped by the inputs ( $e$ and $e c$ ) in some fuzzy rules designed by membership functions.

The widely used membership functions in fuzzy rules include the types of triangle, trapezoid, Gaussian, bell and so on [18]. Triangle and trapezoid belong to linear membership functions, which are the most natural and unbiased. Gaussian and bell membership functions are nonlinear, which earn more applications in the study of fuzzy control. Especially, the Gaussian type obtains the most attentions because that its nonlinear characteristic and distribution curve satisfy the complexity of process control better. However, in order to realize the better control performance, most fuzzy control studies focus on how to give a better rule base in fuzzy controller. Few study has tried to improve the control per-

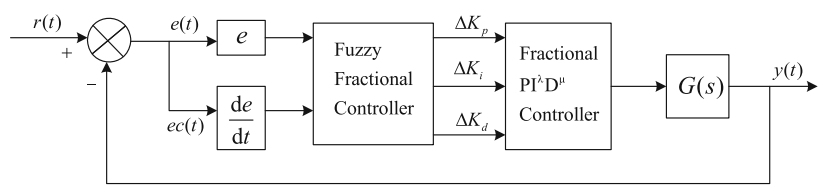

Fig. 4 Block diagram of fuzzy fractional-order PID control 
formance by choosing a better membership function. In this paper, we will extend the existing membership function of Gaussian type to its FO ones. With more comparisons in control experiments, FO membership functions will show their superiority verified in simulation results.

\section{Fractional-order membership functions}

A fuzzy subset $F$ of $X$ associated with a characteristic function is called a fuzzy set. The corresponding characteristic function is called membership function, i.e., $\mu_{F}(x): X \rightarrow$ $[0,1], x \in X$. In this section, we will update the Gaussian membership function by Mittag-Leffler function, and propose a class of FO membership function. As it is known that the Gaussian membership function $\mu_{F}(\cdot)$ is described by

$\mu_{F}(x)=\exp \left[-\frac{1}{2}\left(\frac{x-c}{\sigma}\right)^{2}\right]$,

where $F$ is a fuzzy set, $c$ denotes the core of the membership function, and $\sigma$ is a parameter to decide the width of the membership function.

In recent years, heavy-tailed distributions have drawn more attention from researchers in probability theory related fields. Heavy-tailed distributions own heavier tails than the exponential distribution, and provide powerful tools for modelling some practical anomalous diffusion processes in finance, biochemistry, environmental science and so on [2427]. In this part, we will give a type of FO membership function, which belongs to fat-tailed distributions. Fat-tailed distribution is a kind of heavy-tailed distributions, and it goes to zero as a power $y^{-a}$, for large $y$. Combined with one-parameter Mittag-Leffler function (6), we construct the following FO membership function,

$\mu_{F, \alpha}(x)=E_{\alpha}\left(-\frac{1}{2}\left[\left(\frac{x-c}{\sigma}\right)^{2}\right]^{\alpha}\right)$,

where $F, c$, and $\sigma$ are same with (8), and fractional order $\alpha$ satisfies $0<\alpha \leq 1$.

Remark 1 When $\alpha=1$, FO membership function (9) is equal to the Gaussian one (8). In other words, Gaussian membership function is just a special case of FO membership function (9).

Remark 2 For any $\alpha \in(0,1]$, the FO membership function (9) satisfies

$\mu_{F, \alpha}(c)=E_{\alpha}(c)=1$,

which conforms to the necessary condition of membership function.

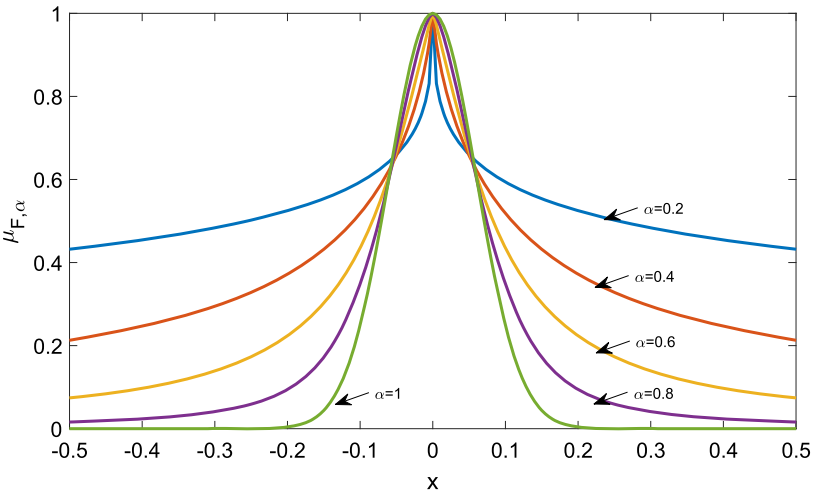

Fig. 5 FO membership function with different orders $\alpha$

Remark 3 FO membership function (9) with $0<\alpha<1$ belongs to fat-tailed distributions, which is a type of heavytailed distributions. It owns fatter tails than the exponential distribution (such as $\alpha=1$ ), which means that samples far from the core of the membership function might occur in higher probability. The proof of its fat-tailed property will be given in Theorem 1.

Theorem 1 When $0<\alpha<1$, the FO membership function (9) is fat-tailed distributions, and its convergence rate to zero follows a power as $|x-c|^{-2 \alpha}$ for large $|x|$.

Proof As $|x| \rightarrow+\infty$, it has

$-\frac{1}{2}\left[\left(\frac{x-c}{\sigma}\right)^{2}\right]^{\alpha} \rightarrow-\infty$.

Based on Lemma 1, it obtains

$$
\begin{aligned}
\mu_{F, \alpha}(x) & =E_{\alpha}\left(-\frac{1}{2}\left[\left(\frac{x-c}{\sigma}\right)^{2}\right]^{\alpha}\right) \\
& =\frac{2 \sigma^{2 \alpha}}{|x-c|^{2 \alpha} \Gamma(1-\alpha)}+O\left(\frac{1}{|x|^{4 \alpha}}\right),
\end{aligned}
$$

when $|x| \rightarrow+\infty$ and $0<\alpha<1$. This completes the proof of Theorem 1.

When $c=0$ and $\sigma=0.06$, the FO membership function with different orders $\alpha$ is shown in Fig. 5. With $0<\alpha<1$, they follow fat-tailed distributions and own different convergence rate according to the change of $\alpha$.

In this paper, we define the scaled input and output by seven fuzzy cases as Negative Big (NB), Negative Medium (NM), Negative Small (NS), Zero (Z), Positive Small (PS), Positive Medium (PM), and Positive Big (PB). For each case, the closed interval for the scaled input or output is set as $\left[\begin{array}{ll}-0.3,0.3\end{array}\right]$. NB and PB are designed as ' $Z$ ' and ' $S$ ' type membership functions respectively. The other cases are all defined by FO membership functions described by (8). We 


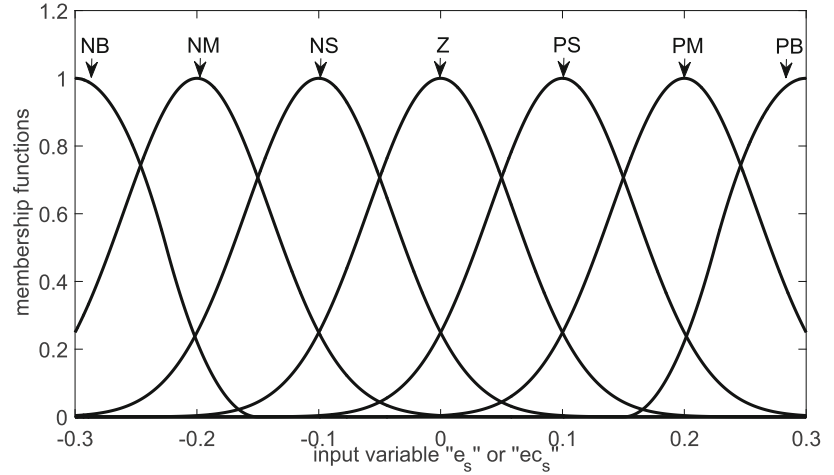

Fig. 6 Membership functions for input variable $e_{s}$ or $e c_{s}$

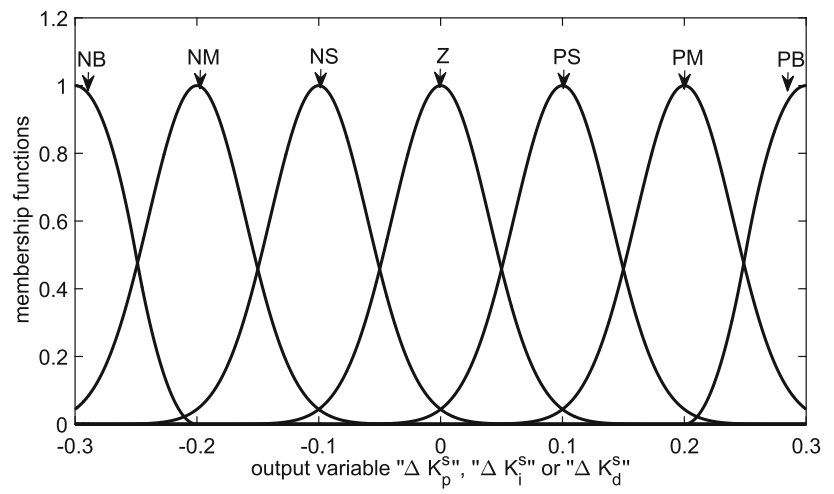

Fig. 7 Membership functions for output variable $\Delta K_{p}^{s}, \Delta K_{i}^{s}$ or $\Delta K_{d}^{s}$

give an example with $\alpha=1$ and $\sigma=0.06$ for the input variable ( $\sigma=0.04$ for the output variable), which is shown in Figs. 6 and 7.

Remark 4 Because the closed interval for the scaled inputs $e_{s}, e c_{s}$ or outputs $\Delta K_{p}^{s}, \Delta K_{i}^{s}, \Delta K_{d}^{s}$ is [-0.3, 0.3], the controlled process error $e$ and its derivative $e c$ should be transformed onto $[-0.3,0.3]$ under scaled maps. Then, $\Delta K_{p}, \Delta K_{i}$ and $\Delta K_{d}$ could be obtained after the gained maps from gained inputs $\Delta K_{p}^{s}, \Delta K_{i}^{s}, \Delta K_{d}^{s}$. With the corresponding gain factors $S_{e}, S_{e c}, S_{p}, S_{i}$ and $S_{d}$, it satisfies the following equations.

$e_{s}=S_{e} \cdot e$,

$e c_{s}=S_{e c} \cdot e c$,

$\Delta K_{p}=S_{p} \cdot \Delta K_{p}^{s}$,

$\Delta K_{i}=S_{i} \cdot \Delta K_{i}^{s}$,

$\Delta K_{d}=S_{d} \cdot \Delta K_{d}^{s}$.

\section{The fuzzy rules}

Based on some given fuzzy rules, the outputs of fuzzy logic controller $\Delta K_{p}^{s}, \Delta K_{i}^{s}$ and $\Delta K_{d}^{s}$ can be achieved according
Table 1 The fuzzy rules for $\Delta K_{p}^{s}$

\begin{tabular}{llllllll}
\hline$e_{s} / e c_{s}$ & $\mathrm{NB}$ & $\mathrm{NM}$ & $\mathrm{NS}$ & $\mathrm{Z}$ & $\mathrm{PS}$ & $\mathrm{PM}$ & $\mathrm{PB}$ \\
\hline $\mathrm{NB}$ & $\mathrm{NB}$ & $\mathrm{NB}$ & $\mathrm{NM}$ & $\mathrm{NM}$ & $\mathrm{NM}$ & $\mathrm{Z}$ & $\mathrm{Z}$ \\
$\mathrm{NM}$ & $\mathrm{NB}$ & $\mathrm{NB}$ & $\mathrm{NM}$ & $\mathrm{NS}$ & $\mathrm{NS}$ & $\mathrm{Z}$ & $\mathrm{PS}$ \\
$\mathrm{NS}$ & $\mathrm{NM}$ & $\mathrm{NM}$ & $\mathrm{NM}$ & $\mathrm{NS}$ & $\mathrm{Z}$ & $\mathrm{PS}$ & $\mathrm{PS}$ \\
$\mathrm{Z}$ & $\mathrm{NM}$ & $\mathrm{NM}$ & $\mathrm{NS}$ & $\mathrm{Z}$ & $\mathrm{PS}$ & $\mathrm{PM}$ & $\mathrm{PM}$ \\
$\mathrm{PS}$ & $\mathrm{NS}$ & $\mathrm{NS}$ & $\mathrm{Z}$ & $\mathrm{PS}$ & $\mathrm{PS}$ & $\mathrm{PM}$ & $\mathrm{PM}$ \\
$\mathrm{PM}$ & $\mathrm{NS}$ & $\mathrm{Z}$ & $\mathrm{PS}$ & $\mathrm{PM}$ & $\mathrm{PM}$ & $\mathrm{PM}$ & $\mathrm{PB}$ \\
$\mathrm{PB}$ & $\mathrm{Z}$ & $\mathrm{Z}$ & $\mathrm{PM}$ & $\mathrm{PM}$ & $\mathrm{PM}$ & $\mathrm{PB}$ & $\mathrm{PB}$ \\
\hline
\end{tabular}

Table 2 The fuzzy rules for $\Delta K_{i}^{s}$

\begin{tabular}{llllllll}
\hline$e_{s} / e c_{s}$ & $\mathrm{NB}$ & $\mathrm{NM}$ & $\mathrm{NS}$ & $\mathrm{Z}$ & $\mathrm{PS}$ & $\mathrm{PM}$ & $\mathrm{PB}$ \\
\hline $\mathrm{NB}$ & $\mathrm{PB}$ & $\mathrm{PB}$ & $\mathrm{PM}$ & $\mathrm{PM}$ & $\mathrm{PS}$ & $\mathrm{Z}$ & $\mathrm{Z}$ \\
$\mathrm{NM}$ & $\mathrm{PB}$ & $\mathrm{PB}$ & $\mathrm{PM}$ & $\mathrm{PS}$ & $\mathrm{PS}$ & $\mathrm{Z}$ & $\mathrm{Z}$ \\
$\mathrm{NS}$ & $\mathrm{PB}$ & $\mathrm{PM}$ & $\mathrm{PS}$ & $\mathrm{PS}$ & $\mathrm{Z}$ & $\mathrm{NS}$ & $\mathrm{NS}$ \\
$\mathrm{Z}$ & $\mathrm{PM}$ & $\mathrm{PM}$ & $\mathrm{PS}$ & $\mathrm{Z}$ & $\mathrm{NS}$ & $\mathrm{NM}$ & $\mathrm{NM}$ \\
$\mathrm{PS}$ & $\mathrm{PM}$ & $\mathrm{PS}$ & $\mathrm{Z}$ & $\mathrm{NS}$ & $\mathrm{NS}$ & $\mathrm{NM}$ & $\mathrm{NB}$ \\
$\mathrm{PM}$ & $\mathrm{Z}$ & $\mathrm{Z}$ & $\mathrm{NS}$ & $\mathrm{NS}$ & $\mathrm{NM}$ & $\mathrm{NB}$ & $\mathrm{NB}$ \\
$\mathrm{PB}$ & $\mathrm{Z}$ & $\mathrm{Z}$ & $\mathrm{NS}$ & $\mathrm{NM}$ & $\mathrm{NM}$ & $\mathrm{NB}$ & $\mathrm{NB}$ \\
\hline
\end{tabular}

Table 3 The fuzzy rules for $\Delta K_{d}^{s}$

\begin{tabular}{llllllll}
\hline$e_{s} / e c_{s}$ & $\mathrm{NB}$ & $\mathrm{NM}$ & $\mathrm{NS}$ & $\mathrm{Z}$ & $\mathrm{PS}$ & $\mathrm{PM}$ & $\mathrm{PB}$ \\
\hline $\mathrm{NB}$ & $\mathrm{NS}$ & $\mathrm{PS}$ & $\mathrm{PB}$ & $\mathrm{PB}$ & $\mathrm{PB}$ & $\mathrm{PM}$ & $\mathrm{NS}$ \\
$\mathrm{NM}$ & $\mathrm{PS}$ & $\mathrm{PS}$ & $\mathrm{PB}$ & $\mathrm{PM}$ & $\mathrm{PM}$ & $\mathrm{PS}$ & $\mathrm{Z}$ \\
$\mathrm{NS}$ & $\mathrm{Z}$ & $\mathrm{PS}$ & $\mathrm{PM}$ & $\mathrm{PM}$ & $\mathrm{PS}$ & $\mathrm{PS}$ & $\mathrm{Z}$ \\
$\mathrm{Z}$ & $\mathrm{Z}$ & $\mathrm{PS}$ & $\mathrm{PS}$ & $\mathrm{PS}$ & $\mathrm{PS}$ & $\mathrm{PS}$ & $\mathrm{Z}$ \\
$\mathrm{PS}$ & $\mathrm{Z}$ & $\mathrm{Z}$ & $\mathrm{Z}$ & $\mathrm{Z}$ & $\mathrm{Z}$ & $\mathrm{Z}$ & $\mathrm{Z}$ \\
$\mathrm{PM}$ & $\mathrm{NB}$ & $\mathrm{NS}$ & $\mathrm{NS}$ & $\mathrm{NS}$ & $\mathrm{NS}$ & $\mathrm{NS}$ & $\mathrm{NB}$ \\
$\mathrm{PB}$ & $\mathrm{NB}$ & $\mathrm{NM}$ & $\mathrm{NM}$ & $\mathrm{NM}$ & $\mathrm{NS}$ & $\mathrm{NS}$ & $\mathrm{NB}$ \\
\hline
\end{tabular}

to the inputs of fuzzy logic controller $e_{s}$ and $e c_{s}$. We employ the fuzzy rules as the follwing two-dimensional form.

FuzzyRules : If $e_{s}$ is $E_{s}$ and $e c_{s}$ is $E C_{s}$, then $\Delta K_{p}^{s}$ is $\Delta \Psi_{p}^{s}, \Delta K_{i}^{s}$ is $\Delta \Psi_{i}^{s}$ and $\Delta K_{d}^{s}$ is $\Delta \Psi_{d}^{s}$,

where $E_{s}, E C_{s}, \Delta \Psi_{p}^{s}, \Delta \Psi_{i}^{s}$ and $\Delta \Psi_{d}^{s}$ denote the fuzzy sets of $e_{s}, e c_{s}, \Delta K_{p}^{s}, \Delta K_{i}^{s}$ and $\Delta K_{d}^{s}$ respectively.

Because each input fuzzy set consists of 7 cases (NB, NM, NS, Z, PS, PM and PB), two inputs $e_{s}$ and $e c_{s}$ own $7^{2}=49$ rules for the maps from $e_{s}$ and $e c_{s}$ to $\Delta K_{p}^{s}, \Delta K_{i}^{s}$ or $\Delta K_{d}^{s}$. In addition, all the rules are concluded in Tables 1, 2 and 3 for $\Delta K_{p}^{s}, \Delta K_{i}^{s}$ and $\Delta K_{d}^{s}$ respectively.

Based on the above fuzzy rules, the relationships between inputs $e_{s}, e c_{s}$ and outputs $\Delta K_{p}^{s}, \Delta K_{i}^{s}$ and $\Delta K_{d}^{s}$ can be obtained. If we choose the FO membership functions in Figs. 


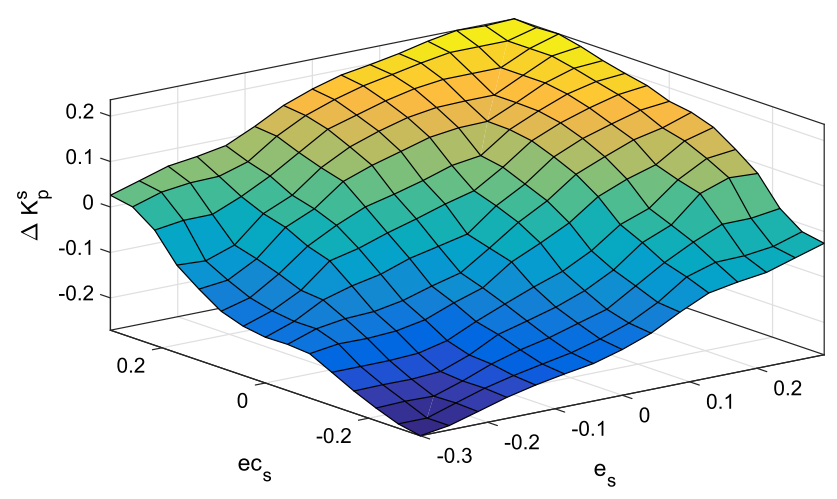

Fig. $8 \Delta K_{p}^{s}$ depended on $e_{s}$ and $e c_{s}$

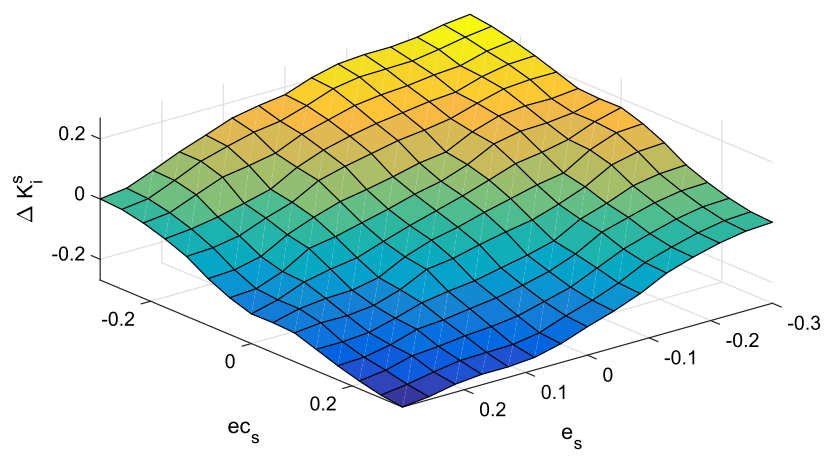

Fig. $9 \Delta K_{i}^{s}$ depended on $e_{s}$ and $e c_{s}$

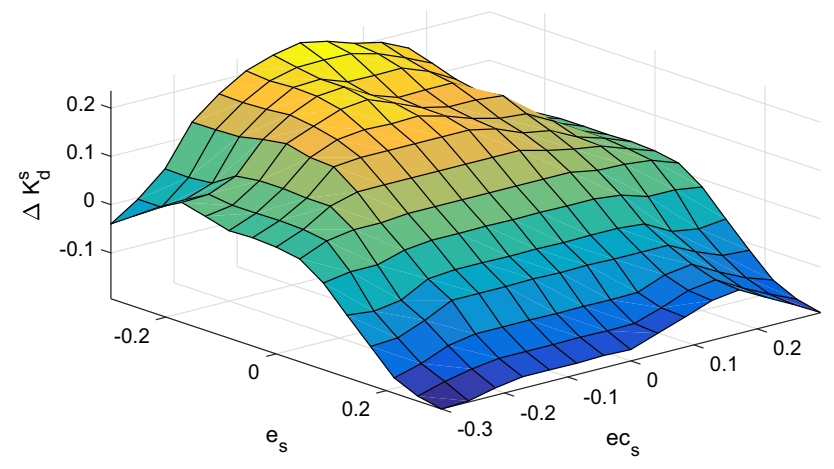

Fig. $10 \Delta K_{d}^{s}$ depended on $e_{s}$ and $e c_{s}$

6 and 7, the exact map values can be achieved under Fuzzy Logic Designer in MATLAB, and are shown in Figs. 8, 9 and 10.

\section{Steps of FFuzzy PID Control}

Under the above presentation of fuzzy logic control, we give the detailed steps of FFuzzy PID control in this subsection.

Step 1: according to characteristics of the controlled FO system, choose the initial controller parameters $K_{p}, K_{i}, K_{d}$, a series of FO membership functions and scaling factors. In other words, determine a group of parameters including of $\alpha, \sigma, S_{e}, S_{e c}, S_{p}, S_{i}$ and $S_{d}$.

Step 2: calculate the input and output membership functions. Based on the 49 rules in Tables 1, 2 and 3, obtain the maps from $e_{s}$ and $e c_{s}$ to $\Delta K_{p}^{s}, \Delta K_{i}^{s}$ or $\Delta K_{d}^{s}$.

Step 3: For $e$ and $e c$ in the controlled FO system, calculate the scaled inputs $e_{s}$ and $e c_{s}$ by

$e_{s}=S_{e} \cdot e$,

$e c_{s}=S_{e c} \cdot e c$,

in order to transform them into $[-0.3,0.3]$. Gain the $\Delta K_{p}^{s}$, $\Delta K_{i}^{s}$ and $\Delta K_{d}^{s}$ according to Step 2, then obtain $\Delta K_{p}, \Delta K_{i}$ and $\Delta K_{d}$ by

$$
\begin{aligned}
\Delta K_{p} & =S_{p} \cdot \Delta K_{p}^{s}, \\
\Delta K_{i} & =S_{i} \cdot \Delta K_{i}^{s}, \\
\Delta K_{d} & =S_{d} \cdot \Delta K_{d}^{s} .
\end{aligned}
$$

Step 4: update the gain coefficients $K_{p}, K_{i}$ and $K_{d}$ by the obtained $\Delta K_{p}, \Delta K_{i}$ and $\Delta K_{d}$.

Step 5: update the fractional order $\alpha$ of membership functions and back to Step 2, until the controlled system obtains the expected control performances.

\section{Examples}

A great variety of factors, for instance, load variations, measurement noise disturbance, pressure impact, gas flow impact, set-point temperature impact and etc, may affect the dynamic performance of temperature control system and bring about parameter uncertainties. In this section, the dynamic control performance and robustness of the studied general type temperature control plants are tested to verify the effectiveness of the proposed control algorithm. In order to make the system in Eq. (2) more general, it is further divided into three specific types by the normalized dead-time ratios (delay $(L) /$ time constant $(T)$ ) [19]. When $L \ll T, L \approx T$, and $L \gg T$, the controlled systems are called lag dominated, balanced lag and delay, and delay-dominated systems respectively.

For comparison, three kinds of controllers i.e. an OPID (Optimal PID used in [36]), an FOPID (Fractional-Order PID used in [36]), an FFuzzy PID (Fractional-order Fuzzy PID proposed in this paper) are designed for each controlled plant.

The Nelder-Mead simplex method is used to optimize the controller parameters and the ITAE indicator is applied as an objective function in the optimization process [20]. In order to proceed fair comparison, the parameters of the FFuzzy PID controller are the same to those used in FOPID controller, which are shown in Table 4 . In the following, the 
Table 4 Controller parameters

\begin{tabular}{lllllll}
\hline & & $K_{p}$ & $K_{i}$ & $K_{d}$ & $\lambda$ & $\mu$ \\
\hline$G_{1}(s)$ & FOPID & 0.3810 & 5.1988 & 5.5785 & 1.0600 & 0.5299 \\
& PID & 3.0002 & 2.7565 & 1.6308 & - & - \\
$G_{2}(s)$ & FOPID & 0.6881 & 0.5201 & 0.3062 & 1.0383 & 0.7458 \\
& PID & 0.1125 & 0.2601 & 0.1356 & - & - \\
$G_{3}(s)$ & FOPID & 0.1462 & 0.7339 & 0.1299 & 0.9882 & 0.2328 \\
& PID & 0.3502 & 0.7800 & 0.1500 & - & - \\
\hline
\end{tabular}

set-point regulation, robustness of gain variations, disturbance rejection and random delay suppression capabilities of the proposed control algorithm, which are quite important in temperature control systems, are verified respectively. Note that the system gain $K$ is normalized into 1 without loss of generality.

Firstly, consider a lag dominated system of Eq. (2) $G_{1}(s)$ with $T=1.1, \alpha=1.5, L=0.105$. The performance indicators of $G_{1}(s)$ under different circumstances are shown in Table 5. The set-point regulation comparison of $G_{1}(s)$ controlled by three different controllers is illustrated in Fig. 11. All of the three responses are acceptable. But the system controlled by the FOPID controller has relatively large overshoot, and the settling time of that with the OPID controller is longer than the other two. Therefore, the best transient performance is achieved by the FFuzzy PID controller. In order to test the robustness of $G_{1}(s)$ controlled by different controllers, $\pm 20 \%$ parameter uncertainties (on $T, K$ ) are added to the controlled system as shown in Fig. 12. It is seen from Fig. 12 that the system controlled by FFuzzy PID controller also outper-

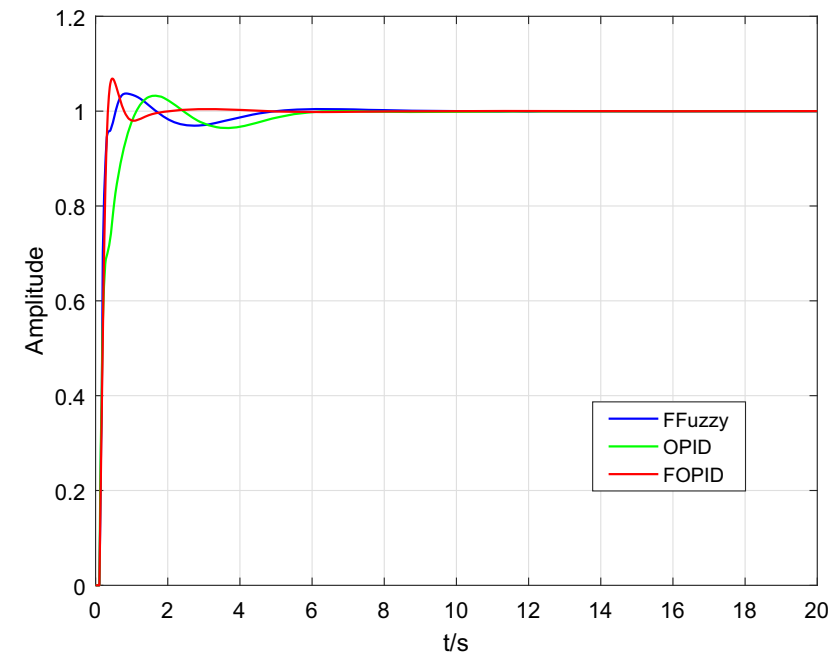

Fig. 11 Set-point regulation performance of $G_{1}(s)$

forms the other two. In Fig. 13, a disturbance signal with -0.2 in amplitude is added to the system at $t=10 \mathrm{~s}$. The disturbance rejection performance of $G_{1}(s)$ with the FFuzzy controller in Fig. 14 demonstrates its superiority compared with the other two curves as well. Finally, a random delay $\in\left[\begin{array}{ll}0, & 0.2\end{array}\right] \mathrm{s}$ is applied to $G_{1}(s)$ instead of the fixed delay $0.105 \mathrm{~s}$. Figure 11 shows the performance comparison of $G_{1}(s)$ with random delay under three different controllers. Clearly, the controlled performance of the FOPID controller has been affected a lot by the random delay. Its overshoot and settling time are quite large. The settling time of $G_{1}(s)$ under the OPID controller in Fig. 11 is the largest, though the corresponding response overshoot is quite small. Therefore, the response of sys-

Table 5 Performance indices of $G_{1}(s)$

\begin{tabular}{llllll}
\hline & Controllers & Overshoot $(\%)$ & Rise time (s) & Peak time (s) & Steady-state error \\
\hline Set-point Regulation & FFuzzy PID & 3.7242 & 0.1734 & 0.8489 & $3.94 \mathrm{E}-06$ \\
& PID & 3.2558 & 0.6489 & 1.6667 & $1.07 \mathrm{E}-05$ \\
& FOPID & 6.8569 & 0.1895 & 0.461 & $5.32 \mathrm{E}-05$ \\
Set-point Regulation with +20\% Para Uncertainties & FFuzzy PID & 5.2427 & 0.2187 & 1.2088 & $9.84 \mathrm{E}-05$ \\
& PID & 6.5707 & 0.584 & 1.5976 & $2.09 \mathrm{E}-05$ \\
& FOPID & 8.1157 & 0.1894 & 0.4869 & $9.19 \mathrm{E}-05$ \\
Set-point Regulation with - 20\% Para Uncertainties & FFuzzy PID & 0.6526 & 0.3647 & 1.2246 & $3.33 \mathrm{E}-05$ \\
& PID & - & 0.7714 & - & $1.36 \mathrm{E}-04$ \\
Disturbance Rejection Performance & FOPID & 0.7312 & 0.2312 & 4.6366 & $3.00 \mathrm{E}-06$ \\
& FFuzzy PID & 2.9863 & 0.2205 & 1.1994 & $4.88 \mathrm{E}-05$ \\
Random Delay Suppression Performance & PID & 3.2589 & 0.5838 & 1.5958 & $4.21 \mathrm{E}-04$ \\
& FOPID & 8.5736 & 0.1817 & 0.4303 & $7.79 \mathrm{E}-05$ \\
& FFuzzy PID & 2.9576 & 0.2600 & 1.0942 & $7.83 \mathrm{E}-05$ \\
& PID & 3.2771 & 0.6300 & 1.5670 & $7.60 \mathrm{E}-06$ \\
& FOPID & 17.2508 & 0.2000 & 0.5202 & $2.19 \mathrm{E}-06$ \\
\hline
\end{tabular}



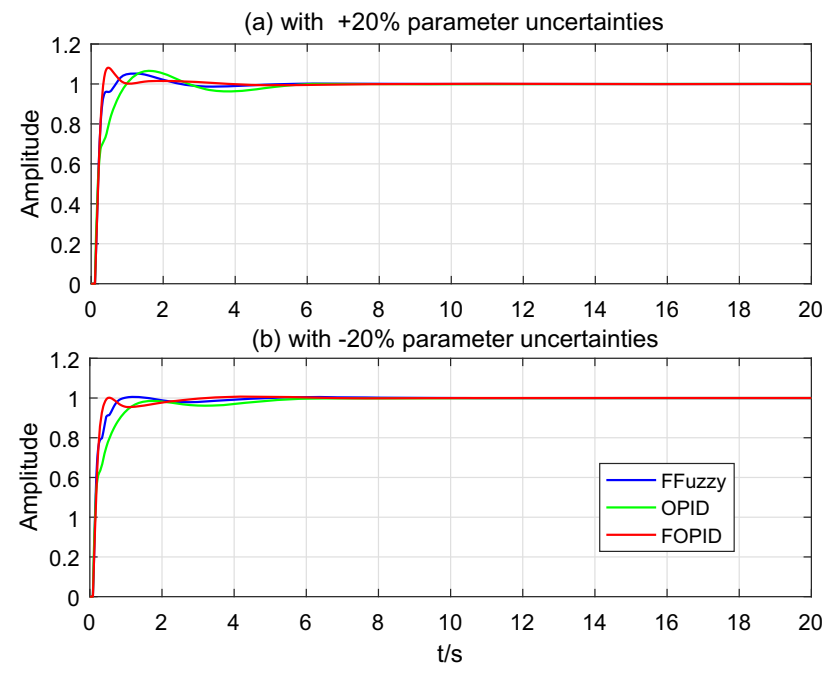

Fig. 12 Robustness with respect to load uncertainties of $G_{1}(s)$

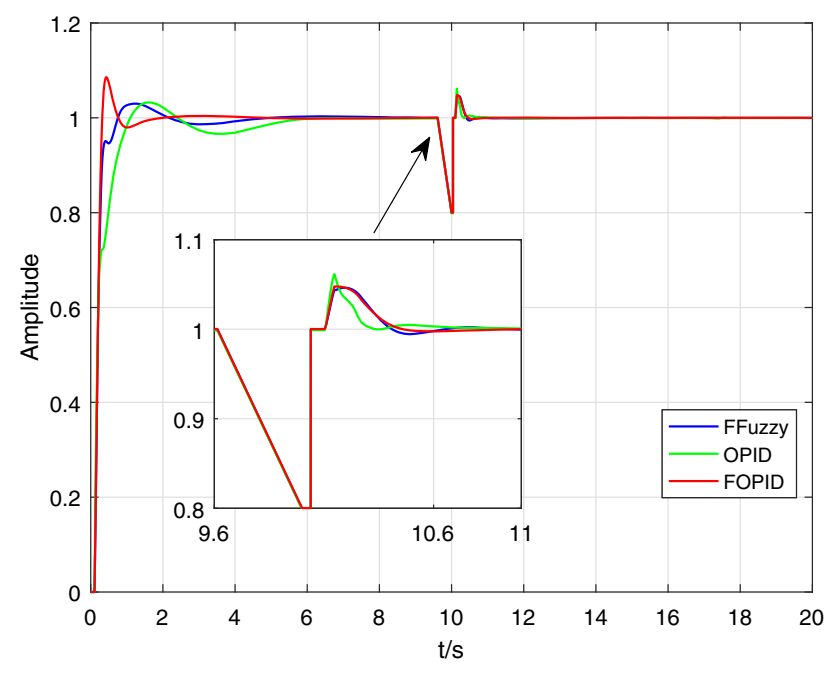

Fig. 13 Disturbance rejection performance of $G_{1}(s)$

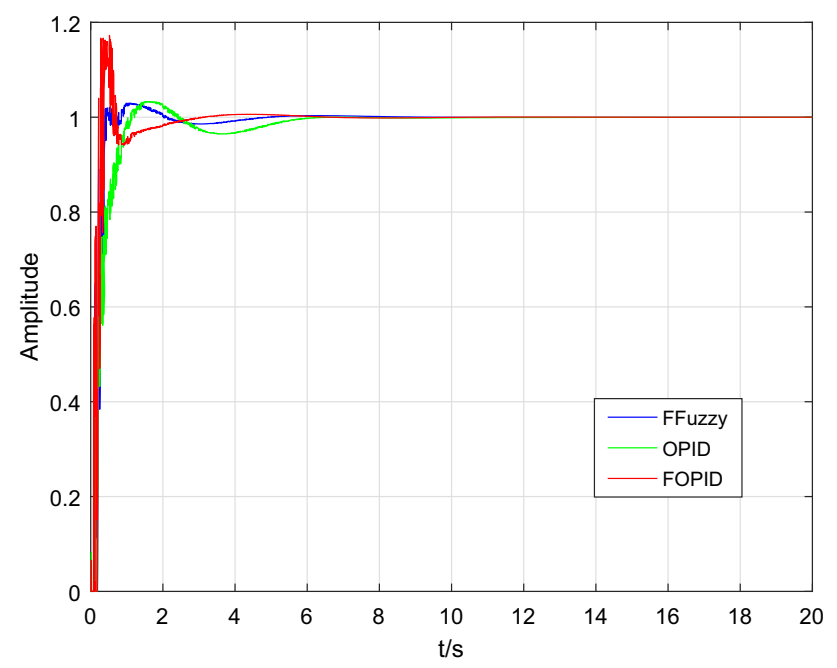

Fig. 14 Random delay suppression performance of $G_{1}(s)$ tem $G_{1}(s)$ with the FFuzzy PID controller still has the most satisfactory control performance. The example shows that the lag dominated system $G_{1}(s)$ controlled by the FFuzzy PID controller has more desirable transient performance as well as robustness compared with that controlled by other controllers.

Then, a balanced lag and delay system with $T=$ 1.5, $\alpha=1.5, L=1$ is considered. The performance indicators of $G_{2}(s)$ under different circumstances are shown in Table 6 . The set-point regulation comparison of $G_{2}(s)$ is demonstrated in Fig. 15. It shows that the rising times of $G_{2}(s)$ controlled by the FOPID and FFuzzy PID controllers are similar, but the undershoot of that under FOPID is too large. The control performance of the OPID controller which oscillates a lot is far from desirable. Figures 16, 17 and 18 are performance comparisons of $G_{2}(s)$ with $\pm 20 \%$ parameter uncertainties (on $T, K$ ), with a disturbance signal at $t=10 \mathrm{~s}$, and with $[0.7,1.3] \mathrm{s}$ random delay instead of fixed delay respectively. The dynamic performances of $G_{2}(s)$ controlled by the FFuzzy PID controllers under these three different conditions are desirable. In contrast, the systems controlled by the FOPID controller always have large undershoots. The step responses under the OPID controller oscillate a lot, so their performances are much worse than that under the other two controllers. Hence, both dynamic performance and robustness of the balanced lag and delay system $G_{2}(s)$ controlled by the proposed controller are better than others.

At last, a delay dominated system with $T=0.05, \alpha=$ 1.5, $L=1$ is investigated. $G_{3}(s)$ has a relatively large delay to time constant ratio $(L / T)$, so it is more difficult to be controlled. Its performance indicators under different circumstances are shown in Table 7. Figure 19 is the set-point regulation of $G_{3}(s)$ under three different controllers. All the responses in Fig. 19 oscillate during the transient process and all the rising times are similar. The overshoot of the system controlled by the OPID controller is much larger than the other two. Meanwhile, the undershoot of $G_{3}(s)$ with the FFuzzy PID controller is the largest. Since $G_{3}(s)$ is quite sensitive, so $\pm 10 \%$ parameter uncertainties (on $T, K$ ) are added in Fig. 20 to test its robustness. Obviously, the system controlled by the FFuzzy PID controller is robust to parameter uncertainties with almost unchanged rising time and overshoot. But the control performances of the FOPID and OPID controllers are sensitive to parameter uncertainties that their performances change a lot under different conditions. The step response comparison of $G_{3}(s)$ with random delay $\epsilon$ $[0.9,1.1] \mathrm{s}$ is shown in Fig. 21. Similarly, the controlled performance of the FFuzzy PID controller outperforms the other two. 
Table 6 Performance indices of $G_{2}(s)$

\begin{tabular}{|c|c|c|c|c|c|}
\hline & Controllers & Overshoot (\%) & Rise time (s) & Peak time (s) & Steady-state error \\
\hline \multirow[t]{3}{*}{ Set-point Regulation } & FFuzzy PID & 3.4463 & 1.145 & 2.9297 & $2.50 \mathrm{E}-04$ \\
\hline & PID & 5.6058 & 4.4115 & 7.1624 & $2.25 \mathrm{E}-05$ \\
\hline & FOPID & 2.7358 & 1.17 & 2.8458 & 7.44E-04 \\
\hline \multirow[t]{3}{*}{ Set-point Regulation with $+20 \%$ Para Uncertainties } & FFuzzy PID & 9.6896 & 1.2094 & 3.1499 & $2.00 \mathrm{E}-04$ \\
\hline & PID & 21.8131 & 3.8458 & 7.3562 & $1.00 \mathrm{E}-03$ \\
\hline & FOPID & 14.1886 & 1.0531 & 3.1499 & $0.00 \mathrm{E}+00$ \\
\hline \multirow[t]{3}{*}{ Set-point Regulation with $-20 \%$ Para Uncertainties } & FFuzzy PID & 0.2777 & 1.2637 & 7.1726 & $1.00 \mathrm{E}-03$ \\
\hline & PID & - & 5.4819 & - & $1.02 \mathrm{E}-01$ \\
\hline & FOPID & 2.2856 & 1.1158 & 8.3329 & 4.49E-01 \\
\hline \multirow[t]{3}{*}{ Disturbance Rejection Performance } & FFuzzy PID & 3.3739 & 1.155 & 2.8502 & $0.00 \mathrm{E}+00$ \\
\hline & PID & 9.8601 & 3.0959 & 5.4982 & $2.70 \mathrm{E}-03$ \\
\hline & FOPID & 2.0161 & 1.2689 & 8.9175 & $2.00 \mathrm{E}-04$ \\
\hline \multirow[t]{3}{*}{ Random Delay Suppression Performance } & FFuzzy PID & 2.4586 & 1.3000 & 3.3000 & $1.22 \mathrm{E}-05$ \\
\hline & PID & 10.9397 & 3.2000 & 5.6000 & $3.70 \mathrm{E}-06$ \\
\hline & FOPID & 2.0287 & 1.3000 & 8.5000 & 2.67E-05 \\
\hline
\end{tabular}

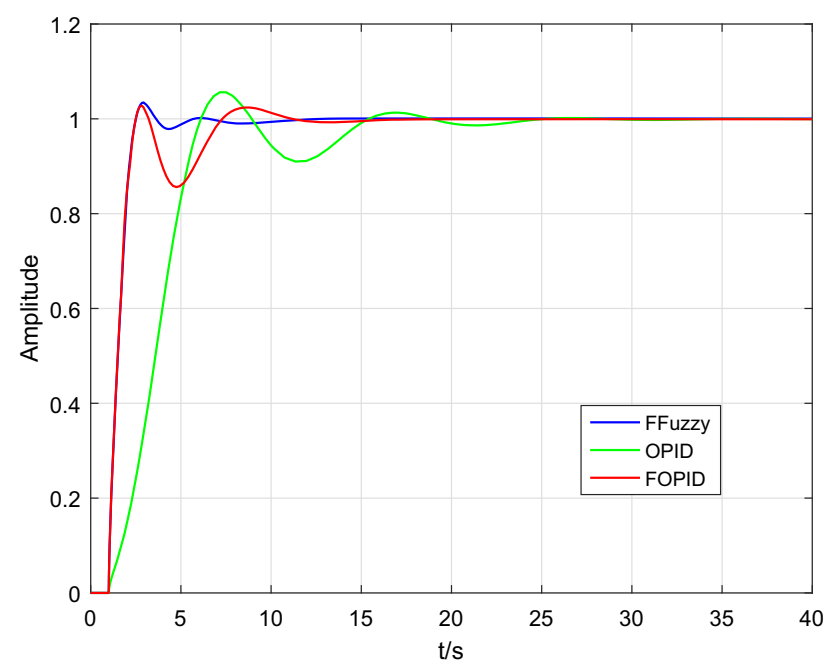

Fig. 15 Set-point regulation performance of $G_{2}(s)$
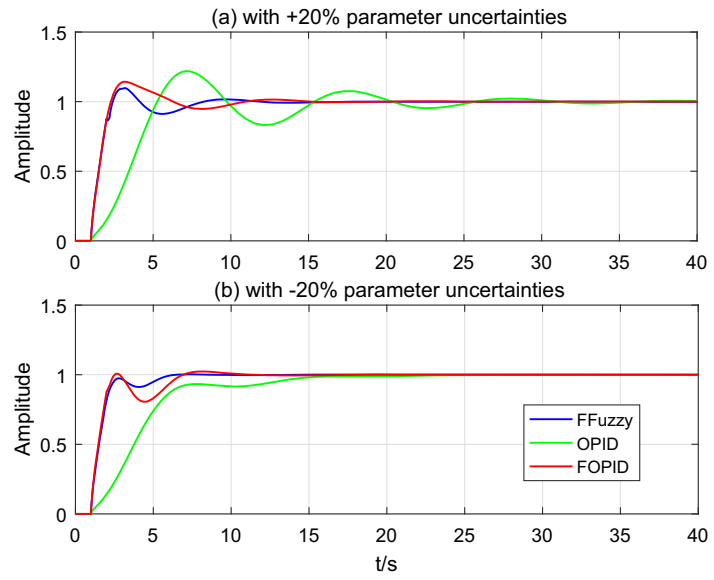

Fig. 16 Robustness with respect to load uncertainties of $G_{2}(s)$

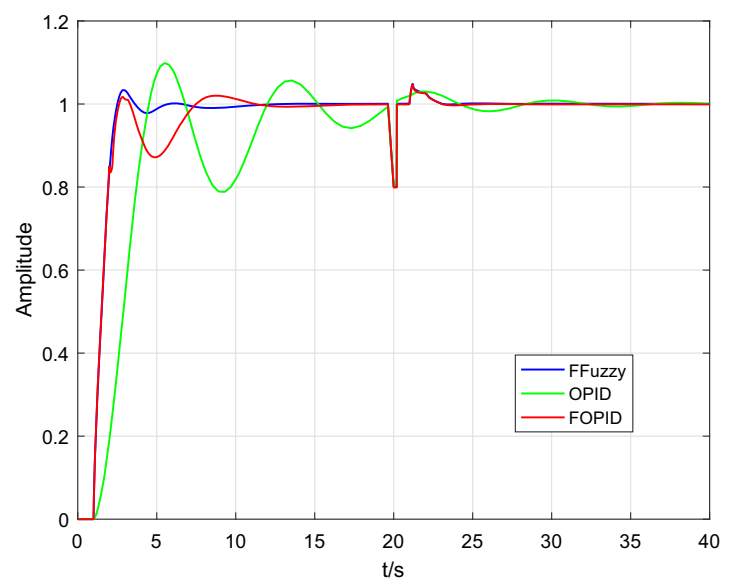

Fig. 17 Disturbance rejection performance of $G_{2}(s)$

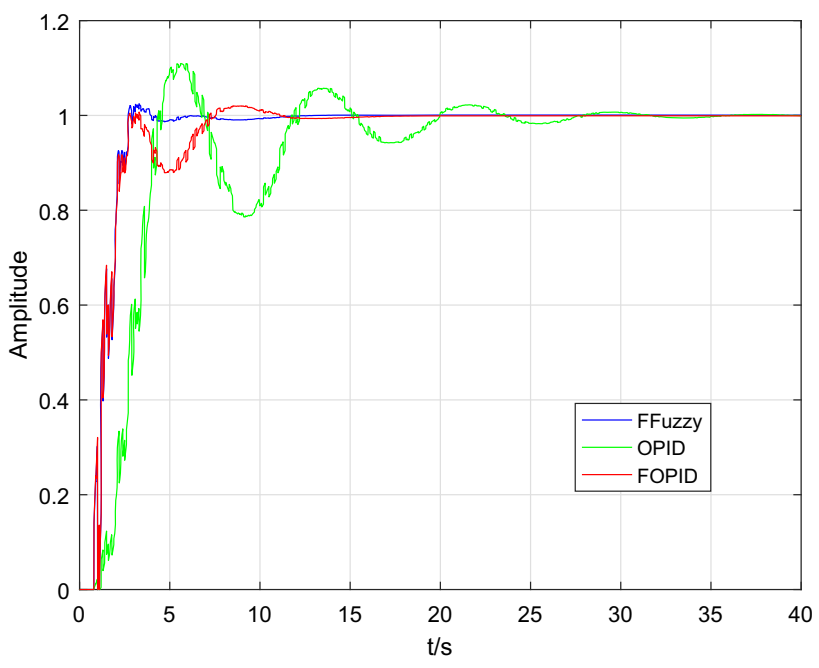

Fig. 18 Random delay suppression performance of $G_{2}(s)$ 
Table 7 Performance Indices of $G_{3}(s)$

\begin{tabular}{|c|c|c|c|c|c|}
\hline & Controllers & Overshoot (\%) & Rise time (s) & Peak time (s) & Steady-state error \\
\hline \multirow[t]{3}{*}{ Set-point regulation } & FFuzzy PID & 2.0914 & 0.9828 & 4.3757 & 4.07E-05 \\
\hline & PID & 21.4166 & 0.7326 & 2.233 & $2.34 \mathrm{E}-06$ \\
\hline & FOPID & 5.0535 & 0.9243 & 2.1792 & 8.31E-06 \\
\hline \multirow{3}{*}{$\begin{array}{l}\text { Set-point regulation with } \\
\quad+10 \% \text { Para Uncertainties }\end{array}$} & FFuzzy PID & 4.9871 & 1.6487 & 3.8665 & $1.31 \mathrm{E}-05$ \\
\hline & PID & 42.5226 & 0.5491 & 2.4177 & 4.30E-06 \\
\hline & FOPID & 23.5585 & 0.7879 & 2.3824 & $3.20 \mathrm{E}-06$ \\
\hline \multirow{3}{*}{$\begin{array}{l}\text { Set-point regulation with } \\
-10 \% \text { Para Uncertainties }\end{array}$} & FFuzzy PID & 1.3871 & 0.9148 & 3.2304 & $1.50 \mathrm{E}-03$ \\
\hline & PID & 1.9204 & 0.8599 & 2.0277 & $0.00 \mathrm{E}+00$ \\
\hline & FOPID & 0.2137 & 1.6555 & 6.2162 & $0.00 \mathrm{E}+00$ \\
\hline \multirow{3}{*}{$\begin{array}{l}\text { Random delay suppression } \\
\text { performance }\end{array}$} & FFuzzy PID & 4.2415 & 0.8325 & 2.9177 & $3.61 \mathrm{E}-06$ \\
\hline & PID & 21.8339 & 0.8132 & 2.2463 & $1.02 \mathrm{E}-05$ \\
\hline & FOPID & 8.6441 & 1.0122 & 2.1198 & $5.62 \mathrm{E}-06$ \\
\hline
\end{tabular}

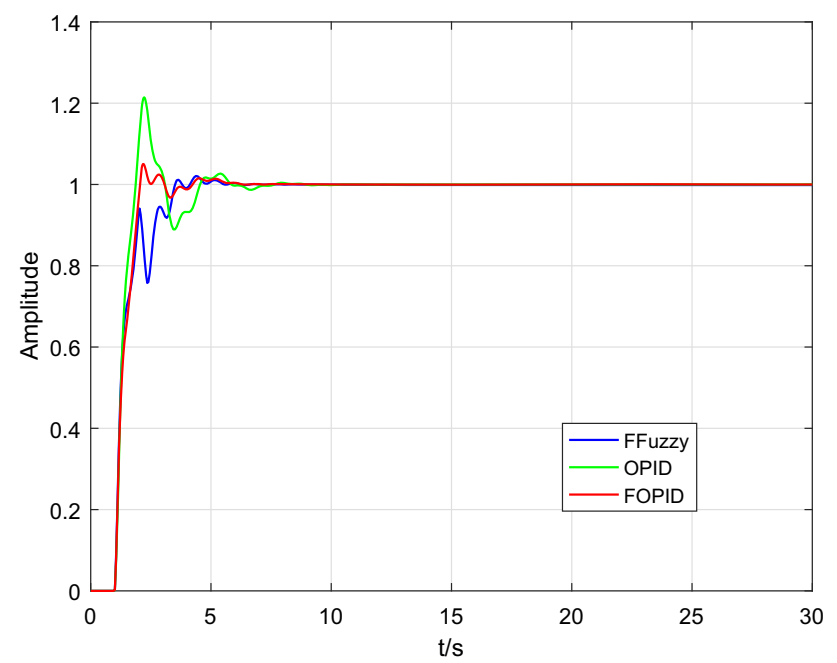

Fig. 19 Set-point regulation performance of $G_{3}(s)$

As it is shown in Table 7 and Fig. 21, the performances of FFuzzy PID, OPID and FOPID controllers in rise time, peak time and steady-state error all present little difference. However, comparing three controllers, the overshoot of PID controller is obviously higher than the other two. Thus, the controlled performance of the FOPID controller is still acceptable, but that of the OPID controller is poor.

In general, all the simulation results show that different types of the studied temperature control system with the proposed controller achieve not only more desirable dynamic performances but also better robustness compared with other controllers. Moreover, the proposed control algorithm shows great potential in improving the control performance of systems with uncertainties or random delay. This is also the superiority of the on-line fuzzy tuning algorithm under fractional-order membership function. The controlled temperature profile with the proposed algorithm could realize
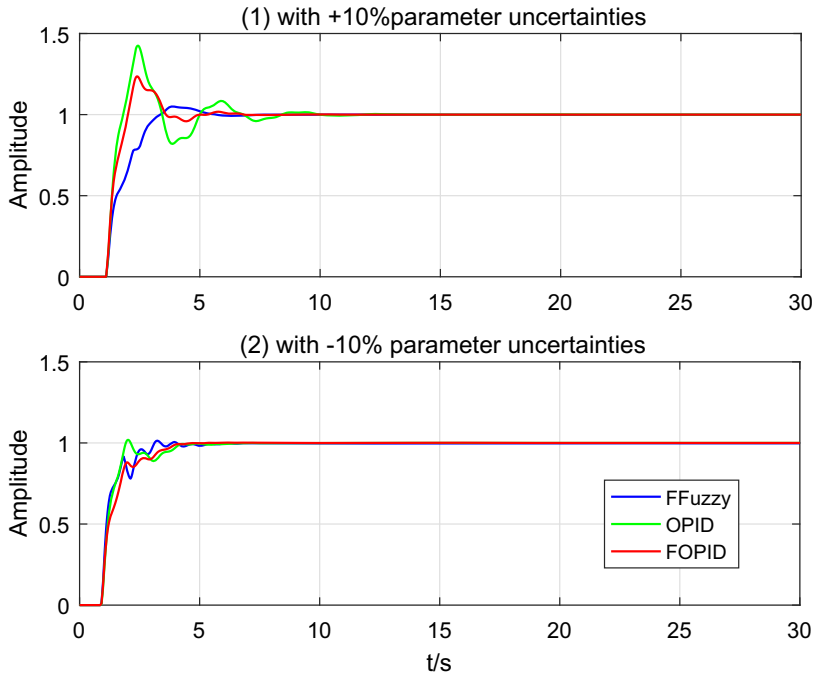

Fig. 20 Robustness with respect to load uncertainties of $G_{3}(s)$

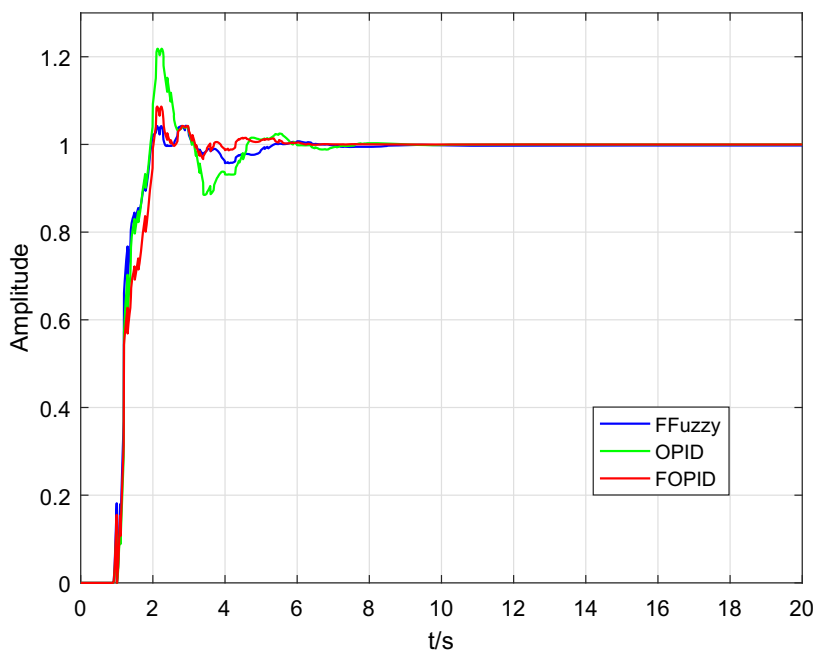

Fig. 21 Random delay suppression performance of $G_{3}(s)$ 
more smooth dynamic performance, relatively small process jitter, superior robustness respect to environment change, measurement noise disturbance and random delay input, which helps a lot in improving production quality and efficiency.

\section{Conclusion}

In this paper, a fuzzy fractional-order PID controller is designed for a general type industrial temperature control process described by a fractional-order elementary system. The fractional-order membership functions presented by employing Mittag-Leffler functions follow fat-tailed distributions. They can provide one more optimization dimension compared with original membership functions. The fuzzy rules and design steps of the proposed fuzzy logic controller are given in detail. The controller parameters can be adjusted on-line according to the model uncertainties and disturbance caused by the environment changes. Moreover, examples of the studied temperature control system are shown to demonstrate the superiority of the proposed control method.

Our future work may concentrate on exploring other practical applications of the proposed control algorithm.

Acknowledgements This study was financially supported by the National Natural Science Foundation of China (Nos. 52001259, 11902252 and 51979229), China Postdoctoral Science Foundation (Nos. 2020M673484 and 2019M663811), the Natural Science Foundation of Shaanxi Province (Nos. 2019JQ-164 and 2020JQ-194), the Young Talent fund of University Association for Science and Technology in Shaanxi, China (No. 20200502).

\section{Declarations}

Conflict of interest The authors declare that they have no known competing financial interests or personal relationships that could have appeared to influence the work reported in this paper.

Open Access This article is licensed under a Creative Commons Attribution 4.0 International License, which permits use, sharing, adaptation, distribution and reproduction in any medium or format, as long as you give appropriate credit to the original author(s) and the source, provide a link to the Creative Commons licence, and indicate if changes were made. The images or other third party material in this article are included in the article's Creative Commons licence, unless indicated otherwise in a credit line to the material. If material is not included in the article's Creative Commons licence and your intended use is not permitted by statutory regulation or exceeds the permitted use, you will need to obtain permission directly from the copyright holder. To view a copy of this licence, visit http://creativecomm ons.org/licenses/by/4.0/.

\section{References}

1. Zhang R, Zou Q, Cao Z, Gao F (2017) Design of fractional order modeling based extended non-minimal state space MPC for temperature in an industrial electric heating furnace. J Process Control 56:13-22

2. Zhang R, Xue A, Gao F (2014) Temperature control of industrial coke furnace using novel state space model predictive control. IEEE Trans Industr Inf 10:2084-2092

3. Zhang R, Sheng W, Lu R, Gao F (2014) Predictive control optimization based PID control for temperature in an industrial surfactant reactor. Chemometr Intell Lab Syst 135:8-62

4. Hu X, Zou Q, Zou H (2018) Design and application of fractional order predictive functional control for industrial heating furnace. IEEE Access 6:66565-66575

5. Liu L, Zhang S, Xue D, Chen YQ (2018) General robustness analysis and robust fractional-order PD controller design for fractional-order plants. IET Control Theory Appl 12:1730-1736

6. Podlubny I (1999) Fractional-order systems and $\mathrm{PI}^{\lambda} \mathrm{D}^{\mu}$-controllers. IEEE Trans Autom Control 44:208-214

7. Zhang S, Liu L, Cui X (2019) Robust FOPID controller design for fractional-order delay systems using positive stability region analysis, International Journal of Robust and Nonlinear Control, $29,5195-5212$

8. Hammouch Z, Mekkaoui T (2018) Circuit design and simulation for the fractional-order chaotic behavior in a new dynamical system. Complex Intell Syst 4:251-260

9. Petras I (2009) Fractional-order feedback control of a DC motor. J Electr Eng 60:117-128

10. Hamamci SE (2007) An algorithm for stabilization of fractionalorder time delay systems using fractional-order PID controllers. IEEE Trans Autom Control 52:1964-1969

11. Vinagre BM, Podlubny I, Dorcak L, Feliu V (2000) On fractional PID controllers: a frequency domain approach. In: Proceedings of IFAC workshop on digital control past

12. Monje CA, Vinagre BM, Feliu V, Chen Y (2008) Tuning and auto-tuning of fractional order controllers for industry applications. Control Eng Pract 16:798-812

13. Pachauri N, Singh V, Rani A (2018) Two degrees-of-freedom fractional-order proportional-integral-derivative-based temperature control of fermentation process. J Dyn Systems Measur Control Trans ASME 140:071006

14. Pachauri N, Rani A, Singh V (2017) Bioreactor temperature control using modified fractional order IMC-PID for ethanol production. Chem Eng Res Des 122:97-112

15. Qin J, Li X, Yang Y (2018) Application of a fractional order PID controller for temperature control in vegetable greenhouses. J Southwest Univers Nat Sci Ed 38:179-182

16. Moon UC, Lee KY (2003) Hybrid algorithm with fuzzy system and conventional PI control for the temperature control of tv glass furnace. IEEE Trans Control Syst Technol 11:548-554

17. Tajjudin M, Ishak N, Rahiman MHF, Arshad NM, Adnan R (2015) Self-tuning fuzzy fractional-order PI controller: design and application in steam distillation process. In: IEEE international conference on control system

18. Harris CJ, Brown M, Moore CG (1993) Intelligent control: aspects of fuzzy logic and neural nets. World Scientific, Singapore

19. Das S, Pan I, Das S, Gupta A (2012) A novel fractional order fuzzy PID controller and its optimal time domain tuning based on integral performance indices. Eng Appl Artif Intell 25:430-442

20. Liu L, Pan F, Xue D (2015) Variable-order fuzzy fractional PID controller. ISA Trans 55:227-233

21. Mishra P, Kumar V, Rana K (2015) A fractional order fuzzy PID controller for binary distillation column control. Expert Syst Appl 42:8533-8549 
22. Sharma R, Rana KPS, Kumar V (2014) Performance analysis of fractional order fuzzy PID controllers applied to a robotic manipulator. Expert Syst Appl 41:4274-4289

23. Kumar A, Kumar V (2018) Performance analysis of optimal hybrid novel interval type-2 fractional order fuzzy logic controllers for fractional order systems. Expert Syst Appl 93:435-455

24. Ibragimov M, Ibragimov R, Walden J (2015) Heavy-tailed distributions and robustness in economics and finance. Springer, New York

25. Pisarenko V, Rodkin M (2010) Heavy-tailed distributions in disaster analysis. Springer, Netherlands

26. Lachos VH, Angolini T, Abanto-Valle CA (2011) On estimation and local influence analysis for measurement errors models under heavy-tailed distributions. Stat Pap 52:567-590

27. Chun SU (2014) Heavy-tailed distributions and their applications

28. Liu L, Tian S, Xue D, Zhang T, Chen Y (2019) Industrial feedforward control technology: A survey. J Intell Manuf 30:2819-2833

29. Liu L, Tian S, Xue D, Zhang T, Chen Y, Zhang S (2019) A review of industrial MIMO decoupling control. Int J Control Autom Syst $17: 1246-1254$

30. Podlubny I (1998) Fractional differential equations: an introduction to fractional derivatives, fractional differential equations, to methods of their solution and some of their applications, 198. Academic Press, New York
31. Zhang S, Yu Y, Wang H (2015) Mittag-leffler stability of fractionalorder Hopfield neural networks. Nonlinear Anal Hybrid Syst 16:104-121

32. Zhang S, Liu L, Xue D (2020) Nyquist-based stability analysis of non-commensurate fractional-order delay systems. Appl Math Comput 377:125111

33. Magin RL (2006) Fractional calculus in bioengineering. Begell House Redding

34. Zhang S, Liu L, Xue D, Chen Y (2020) Stability and resonance analysis of a general non-commensurate elementary fractional-order system. Fract Calc Appl Anal 23:183-210

35. Wang L, Liu J (2012) Data regularization for a backward timefractional diffusion problem. Comput Math Appl 64:3613-3626

36. Xue D (2017) Fractional-order control systems: fundamentals and numerical implementations. de Gruyter, Berlin

Publisher's Note Springer Nature remains neutral with regard to jurisdictional claims in published maps and institutional affiliations. 